\title{
Evaluation of System for Economically Viable Thermal Power Plant Operation
}

\author{
Martin BRICL, Jurij AVSEC
}

\begin{abstract}
Taking into consideration the impacts of global warming and strict European Union policy 2030 climate \& energy framework, it is imminent for conventional thermal power plants to modernize their infrastructure for achieving economically viable operation on demanding electricity market. In the scope of the paper is presented author's individual research work - economic evaluation of conventional thermal power plant operation with solar central receiver system and flue gas desulphurization installation. The goal of research work is to determine whether the designed model is profitable on current European electricity market or not. Based on analytical calculations and gathered numerical data for the designed model, a program code was generated in mathematical environment Matlab, that enables simulation of operation for the designed model in the annual time period. Positive and pessimistic scenarios were analyzed. Results are presented numerically and also graphically and show a positive contribution to the economically viable operation of conventional thermal power plants.
\end{abstract}

Keywords: thermal power plant; economically viable operation; a solar central receiver system; renewable technologies; flue gas desulphurization

\section{INTRODUCTION}

A big step forward has been made in last decade on development of solar central receiver systems. They are a crucial part of energy infrastructure to minimize the use of fossil fuels for electricity production, and they can produce significant amounts of electricity as well as be capable of storing energy in the form of the heat [1]. Design and operating of the central solar receiver system with the central tower is well presented in the article Design and implementation plan of a $10 \mathrm{MW}$ solar tower power plant based on volumetric-air technology in Seville (Spain), published in Proceedings of Solar Powers Life - Share the Energy, 2000 by Manuel Romero and Maria J. Marcos [2]. Combining small CRS and Organic Rankine Cycle is presented in the work of Matthew S. Orosz with the title Small-scale solar ORC system for distributed power [3]. Our work, as presented hereinafter, is focused on the evaluation of the economically viable operation of a conventional thermal power plant in combination with CRS and FGD systems.

\section{CHANGED MARKET CONDITIONS}

Realizing the side effects of the global warming, the European Union sets a goal to produce in $203050 \%$ of its consumed energy from renewable sources. Current part of the produced energy from renewable sources is at $29 \%$. To achieve this goal, we need to define milestones. First, it is a commitment of every individual European member state to intentionally and systematically increase the share of energy from renewable sources until 2030. As a result, abandoning the exceeded use of fossil fuels will save the European Union up to 20 billion $€$ annually. The mechanism, which is used to force large energy and electricity producers to turn green, is the well-known EU ETS (European Union Emission Trading System) [4]. Every large factory, thermal power plant, aviation companies, and other similar polluters receive emission coupons that allow them to emit greenhouse emissions $\left(\mathrm{CO}_{2}\right)$ into our atmosphere. In case the polluters exceed the amount of allowed emitted greenhouse emissions, they need to purchase additional emissions coupons. This is a new direct cost for thermal power plants, which raises its operational costs and consequently its electricity market price. Therefore, thermal power plants will need to find a solution, how to optimize their operating procedures to be able to compete with other electricity producers. They also need to assure that electricity produced from thermal power plants is justified economically and ecologically. In Figure 1 the average hourly market price movement for electricity is presented where we can observe, how the leading role in dictating the price is becoming the current hourly electricity price and that is the main cause of narrowing the price difference between the base and peak daily electricity price.

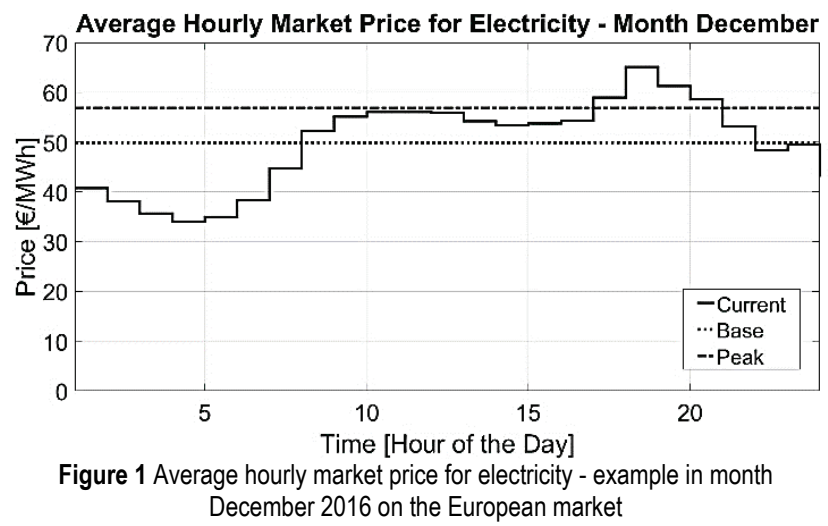

\section{CONVENTIONAL THERMAL POWER PLANT}

The conventional thermal power plant is based on the Rankine cycle [5] that consists of the boiler, a steam turbine that drives an electricity generator, condenser, and boiler pump. The primary fuel for this kind of power plant is coal, but to achieve a higher energy efficiency of the steam boiler, it also burned heavy oil in a mixture of coal [6]. Usually, all flue gases from a steam boiler, that contain ash particles, sulfur dioxide, carbon dioxide, and nitrogen oxides [7], are emitted in our atmosphere through a stack and they get in contact with air, that we all breathe and rainfall, that falls on the ground. Ash particles are dangerous for our health because they can cause serious health problems for human lungs. Sulfur dioxide, as well as nitrogen oxides, is responsible for smog in our cities and 
acid rain that heavily inflicts forests, monuments, and buildings.

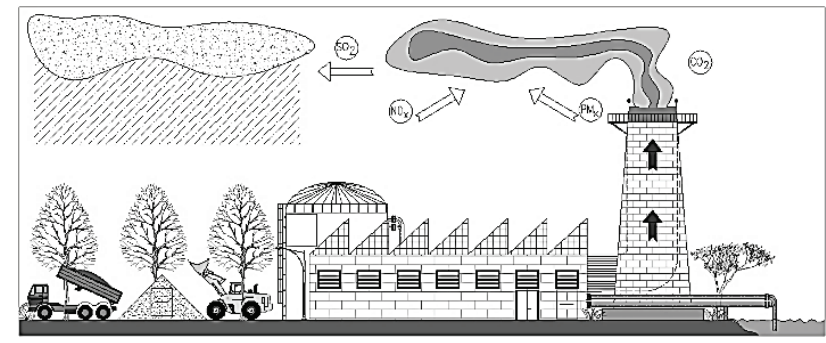

Figure 2 Drawing of a conventional power plant that uses coal and heavy oil as primary fuel and its effects on the environment and human health

As known, the most harmful greenhouse gas is carbon dioxide. In flue gases from the thermal power plant as presented in Fig. 2, the amount of carbon dioxide is immense. This affects our environment because the greenhouse effect is amplified with every additional ton of carbon dioxide that is released into our atmosphere. This is the reason why we should start searching for the alternative source of energy that will help reduce the use of fossil fuel in thermal power plant and will consequently reduce emitted amounts of greenhouse gases into our atmosphere. Hereinafter we will present our proposed model how we could modernize conventional thermal power plants in order to achieve lower fossil fuel consumption, release lower amounts of greenhouse gas emissions and $P M_{x}$ pollutants into our atmosphere and prevent unnecessary human health hazards and the phenomenon of acid rain. The lower fossil fuel consumption amounts of greenhouse gas emissions and $P M_{x}$ pollutants will be achieved with adding to conventional thermal power plant a solar module called CRS - Central Solar Receiver System, that produces steam out of solar irradiance and causes that proportionally lower amount of steam is needed from the steam boiler. That directly affects fossil fuel consumption and pollutant emitted in the atmosphere. The lower amount of Sulphur dioxide will be achieved with flue gas desulphurization unit whose main task is to scrub all acid components, primarily $\mathrm{SO}_{2}$ from flue gases from the fossil fuel-fired steam boiler [8]. Of course, all these additional systems have an impact on the economic performance of a conventional thermal power plant and that is why the economic analysis of conventional thermal power plant modernization is crucial to be analyzed.

\section{PROPOSED REVITALIZATION MODEL}

Proposed revitalization model for conventional thermal power plants is addition of solar central receiver system and flue gas desulphurization unit to the existing steam cycle in a thermal power plant. In Figure 3, we can see the proposed model. In the left square is presented Rankine cycle which is the base of any thermal power plant. Fuel enters the burning chamber in the steam boiler where steam is produced. That steam drives a steam turbine and generator that generates the electricity. From steam turbine steam goes into the condenser where it condensates into the water. Water is then transported to the steam boiler with the help of condensate pump and boiler pump. Both pumps have a task to maintain the sufficient working fluid pressure in the Rankine cycle [9]. The steam boiler has a capacity of 119.25 MW and steam turbine is designed for the output on the shaft of $39.3 \mathrm{MW}$.

In the center of Figure 3 a solar central receiver system is shown. It consists of central tower and heliostat field that sends sunbeams to one point on the top of the central tower. On top of the central tower is stationed a solar receiver that transfers heat from the sunbeams to molten salt [10]. Molten salt is a working fluid in the solar cycle because it can withstand high temperatures (exceeding $500{ }^{\circ} \mathrm{C}$ ) [11] that concentrated sunbeams produce. The solar central receiver system is not complete without hot and cold molten salt tanks that are required for optimal performance of the solar cycle. For heat exchange between conventional Rankine cycle and solar central receiver system cycle a heat steam generator is responsible that allows passage of heat from molten salt (solar cycle) to water and consequently to steam (Rankine cycle). The amount of steam produced from solar cycle depends on the amount and quantity of solar irradiance for the desired geographical location [12]. Calculation of this model is made for the geographical location of the city Velenje, Slovenia [13]. The designed thermal power output of a solar central receiver system is $50 \mathrm{MW}$ and it is achieved with the help of 540 heliostats that are carefully mounted into the heliostat field [14]. Each heliostat has designed an effective reflection surface of $119,9 \mathrm{~m}^{2}$.

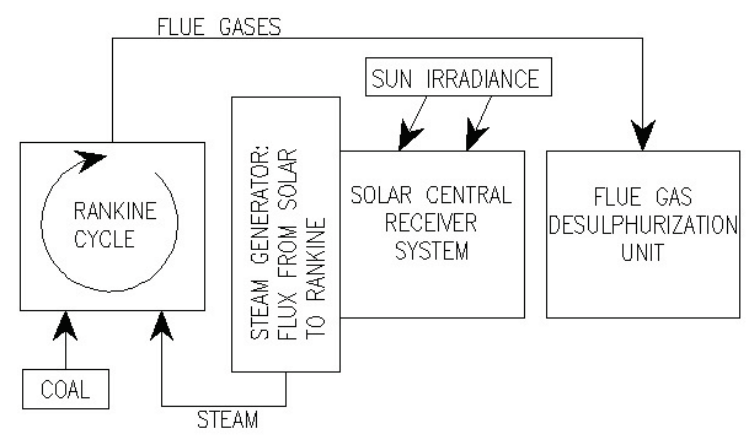

Figure 3 Proposed model for thermal power plant revitalization; left is conventional Rankine cycle, in the middle is solar central receiver system and on the right is flue gas desulphurization unit

In the right square of Fig. 3 is presented a flue gas desulphurization unit that ensures that the lowest amounts of $P M_{x}$ particles and concentrations of $\mathrm{SO}_{2}$ are emitted to the atmosphere from the coal-fired steam boiler. This flue gas desulphurization unit is based on wet calcite process for cleaning of flue gases. This process is the most efficient and economically acceptable for big thermal power plants where big amounts of acid components need to be removed from flue gases. The most important element of the cleaning unit is absorber, where all chemical reactions take place. The absorber is constructed with stainless steel because of the acid environment in it. A by-product of this process is gypsum, which can be reused in the cement industry.

\section{ECONOMIC ANALYSIS}

Economic analysis for the designed model was developed in computer program environment Matlab. The main reason to develop the program code in the mathematical environment was to determine whether this 
proposed model is profitable on electricity market under current conditions, or not. The following empirical equations were used in building the program code for cost analysis. The given result of these equations gives us the data for further cost analyzing of the proposed system. In Tab. 1 the nomenclature of the used parameters in equations is explained [15].

Table 1 Equations parameters

\begin{tabular}{|c|c|c|}
\hline Symbol & Meaning of the symbol & Unit \\
\hline$A$ & Surface & $\mathrm{m}^{2}$ \\
\hline$H$ & Height & $\mathrm{m}$ \\
\hline$I$ & Costs & $/$ \\
\hline$S$ & Scaling factor & $\mathrm{m}^{3}$ \\
\hline$V$ & Volume effect & $/$ \\
\hline$p r$ & Progress ratio & $/$ \\
\hline$p i$ & Price index & \\
\hline
\end{tabular}

For placing the mentioned solar system in the environment, we need to purchase enough land where building the system as this will be allowed. The cost of land is defined as the area of needed land in square meters, multiplied with the price for a square meter of land.

$I_{\text {land }}=A_{\text {land }} \cdot I_{\text {per m}}{ }^{2} \cdot$

Together with acquiring enough space on suitable location, also the basic infrastructure needs to be developed on site - service roads, water drainages, a network for communication and electricity dispatching. The costs of basic infrastructure are defined as follows.

$I_{\text {infrasturcture }}=I_{\text {improvement }}^{0} \cdot\left(\frac{A_{\text {terrain }}}{A_{\text {terrain }}^{0}}\right)^{S_{\text {improvement }}^{0}}$.

In Tab. 2 are presented the direct costs of building the heliostat field.

Table 2 Direct costs of heliostats
\begin{tabular}{|l|c|c|}
\hline \multicolumn{1}{|c|}{ Direct costs of the heliostat } & $\begin{array}{c}\text { Cost } \\
€ / \text { unit }\end{array}$ & $\begin{array}{c}\text { Common cost } \\
\text { mio } €\end{array}$ \\
\hline Concrete & $179 € /$ unit & 0,18 \\
\hline Steel construction & $4382 € /$ unit & 4,50 \\
\hline Electrical drives & $6107 € /$ unit & 6,30 \\
\hline Mirrors & $3755 € /$ unit & 3,80 \\
\hline Control and communication & $915 € /$ unit & 0,90 \\
\hline Network connections & $725 € /$ unit & 0,75 \\
\hline Development & $381 € /$ unit & 0,39 \\
\hline Assembly & $375 € /$ unit & 0,38 \\
\hline Optical enhancements & $95 € /$ unit & 0,098 \\
\hline & Together & 17,298 \\
\hline
\end{tabular}

One of the main costs of the central receiver system is also the central tower on top of which the receiver of the sunbeams is positioned. With the following equation, the cost of the central tower is defined.

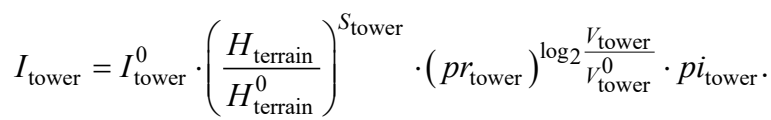

As mentioned previously, on the top of the central tower, the solar receiver is positioned. The cost of the receiver is defined with Eq. (4).

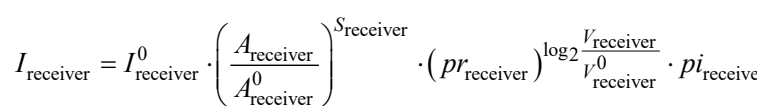

In Tab. 3 the indirect costs of the heliostats are presented. The indirect cost is mainly the engineering services and designing of the solar system, followed by the production and assembly with special tools and rented construction machinery.

Table 3 Indirect costs of heliostats

\begin{tabular}{|l|c|}
\hline \multicolumn{1}{|c|}{ Indirect costs of the heliostat } & Cost [€] \\
\hline Designing & $250000,00 €$ \\
\hline Production and assembly space \& tools & $800000,00 €$ \\
\hline Rent of Construction machinery & $200000,00 €$ \\
\hline Together & $1250000,00 €$ \\
\hline
\end{tabular}

High initial investment costs for the central solar receiver systems, presented in Tab. 4, are present also because of the expensive equipment for energy conversion and storage. Such are steam generator, reservoirs for molten salt and also communication and control system.

Table 4 Equipment for energy conversion

\begin{tabular}{|c|c|}
\hline Equipment for energy conversion & Cost in mio $[€]$ \\
\hline Reservoirs for molten salt & 26,5 \\
\hline Steam generator & 3,0 \\
\hline Control system & 2,0 \\
\hline Together & 31,5 \\
\hline
\end{tabular}

Hereinafter in Fig. 4 are graphically presented proportional investment costs for a considered system.

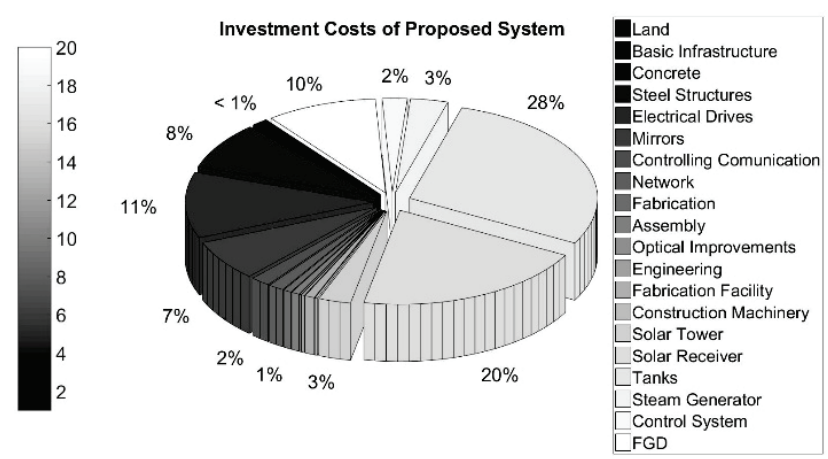

Figure 4 Investment costs of the considered system

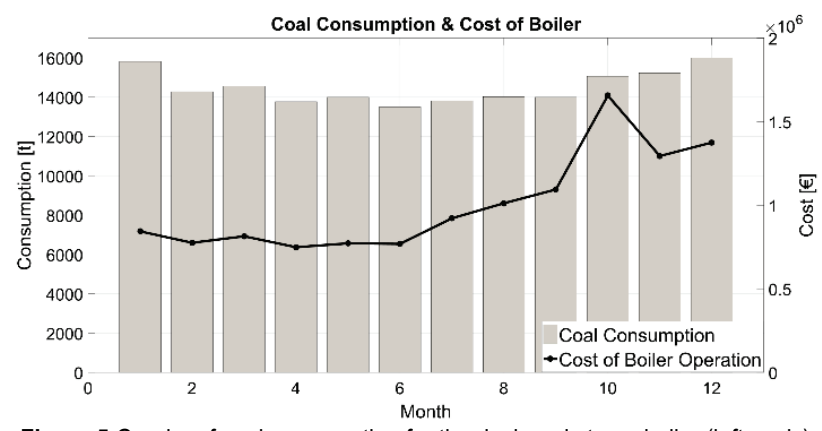

Figure 5 Graphs of coal consumption for the designed steam boiler (lefty-axis) and its operational costs (righty-axis) for a yearly operation period

\subsection{Steam Boiler}

For smooth steam boiler operation, we need to assure a constant flow of fossil fuel into its burning chamber. The designed steam boiler has fuel consumption (coal) of 0,378 $\mathrm{t} / \mathrm{h}$. Because the price of coal varies by market, so do also 
the operational costs of a steam boiler. In Fig. 5 we can see coal consumption and cost of the steam boiler for an ordered period of operation. As mentioned coal market price has a big impact on direct boiler costs. Notice the operational costs of the boiler at the end of the year. Although the consumption of coal is not significantly higher, the cost of boiler operation is higher because of costlier coal on market.

\subsection{Flue Gas Desulphurization Unit}

This unit is intended for cleaning flue gases that exit steam boiler and would conventionally exit thermal power plant through the stack. In order to clean flue gases, there should be placed an absorber between steam boiler and stack. In absorber, chemical reactions between acid components from flue gases and reagent take place. A suitable reagent for this type of flue gas cleaning is limestone that is processed into limestone suspension that is used for spraying flue gases. The technology of wet flue gas desulphurization is the most suitable for thermal power plant [16]. However, it presents an additional cost to the operating of the thermal power plant. For cleaning unit to work properly and sufficiently we need to provide necessary supplies. This is electricity for the cleaning unit, process water, reagent - limestone, periodically professional maintenance, and employees that will operate and control the cleaning unit. All aforementioned supplies present additional cost, which is reflected on electricity and reagent market prices, working force salaries, transport costs for limestone etc. Costs for desulphurization unit for the designed model are presented in Tab. 5 .

Table 5 Flue gas desulphurization unit operational costs

\begin{tabular}{|l|c|c|}
\hline \multirow{2}{*}{\multicolumn{1}{|c|}{ Expense }} & \multicolumn{2}{c|}{ Data } \\
\cline { 2 - 3 } & Value & Unit \\
\hline Cost of electricity & 24,74 & $€ / \mathrm{h}$ \\
\hline Cost of process water & 0,85 & $€ / \mathrm{h}$ \\
\hline Cost of reagent & 34,10 & $€ / \mathrm{h}$ \\
\hline Cost of maintenance & 0,10 & $€ / \mathrm{h}$ \\
\hline Cost of employees & 4,00 & $€ / \mathrm{h}$ \\
\hline Total costs & 63,79 & $€ / \mathrm{h}$ \\
\hline
\end{tabular}

Chemical reactions inside absorber strip acid components from flue gases with the help of spray that consists out of limestone suspension. A by-product of this cleaning process is gypsum in which are bonded acid components that would instead exit into our atmosphere and cause acid rain that affects our forests, environment and our health.

\subsection{Carbon Dioxide Emission Allowances}

Every thermal power plant inside the European Union is under its climate regulations. As part of regulations are also carbon dioxide emission allowances. Carbon dioxide is number one greenhouse gas and as such, it is taxed with the help of emission allowances. Emission allowances are issued and regulated by the European Union for every individual state. The price of $\mathrm{CO}_{2}$ emission allowances is market driven, which means that offer and demand are factors for price changes. Current price for carbon dioxide emission allowances is under $10 € /$ tone of emitted greenhouse gas into our atmosphere. In Figure 6 we can see the predicted amount of emitted carbon dioxide emissions in the atmosphere and corresponding cost of carbon dioxide emission allowances. In order for electricity producers to start investing in new technologies and exploiting renewable sources of energy, the conventional way of producing electricity must become too expensive. With the scheme ETS - European Trading System, the cost of emission allowances is not negligible anymore. This additional expense affects directly the profitability of thermal power plant and as such, it is desired to be minimized. This can be achieved with reduced consumption of fossil fuels and the deliberate exploiting of renewable energy sources. This idea is implemented in our proposed model and it helps to increase the profitability of thermal power plant operation.

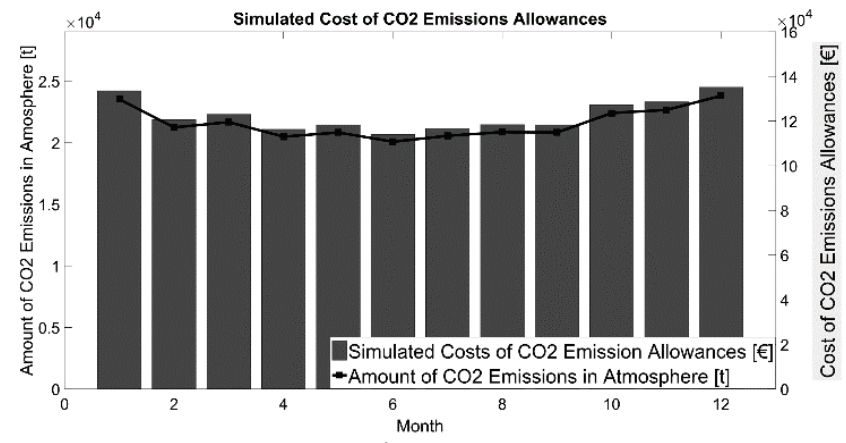

Figure 6 The simulated amount of emitted carbon dioxide emissions in the atmosphere (left) and the cost of carbon dioxide allowances (right)

\subsection{Economic Simulation of Proposed Model}

Economic analysis for the proposed model was made with help of code that we generated in Matlab program environment. Hereinafter are presented, in the scope of Fig. 7 and Fig. 8, the graphs that present economic simulation of the proposed thermal power plant model, for two preselected months - December and July. The graphs include curve for base electricity price, steam boiler operational costs, daily profit from CRS electricity production and total profit from electricity sale for the proposed thermal power plant model. As expected, we can see in Fig. 7 that electricity production in the month December, with help of solar central receiver system, is lower than in the month July as shown in Fig. 8. Every hour of sun irradiance helps to produce steam from solar CRS cycle and also helps to reduce use of fossil fuel and carbon dioxide emissions. That means lower operational costs and higher profit from electricity sale. The graph is constructed with the help of Matlab code and presents average operational day in the considered month. Operation and power production from the solar central receiver is directly connected to the solar irradiance-important is the duration and intensity of solar irradiance. That is why in night hours central receiver system does not produce any power. With sunrise, solar central receiver system starts to operate and achieves its peak at the midday. At the time when solar central receiver system is illuminated by the sun, it produces heat that helps forming additional steam that is used by a steam turbine in the Rankine cycle. Consequently, the steam boiler costs with FGD unit are lowered. 
Economic Simulation of Model Behaveour for Average Day in December

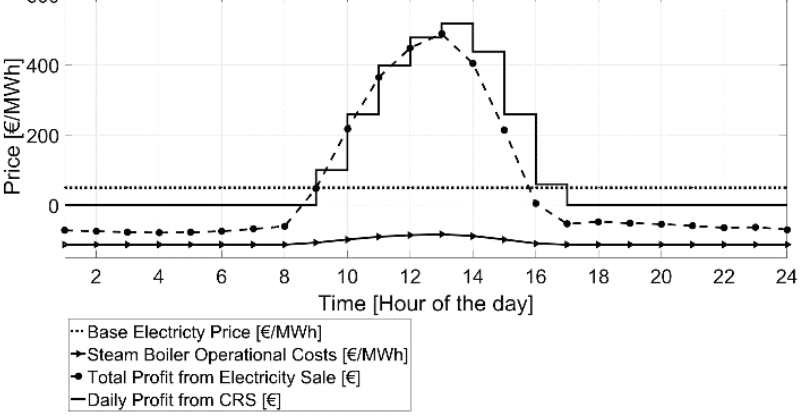

Figure 7 Economic simulation of the proposed model for the average day in the month of December

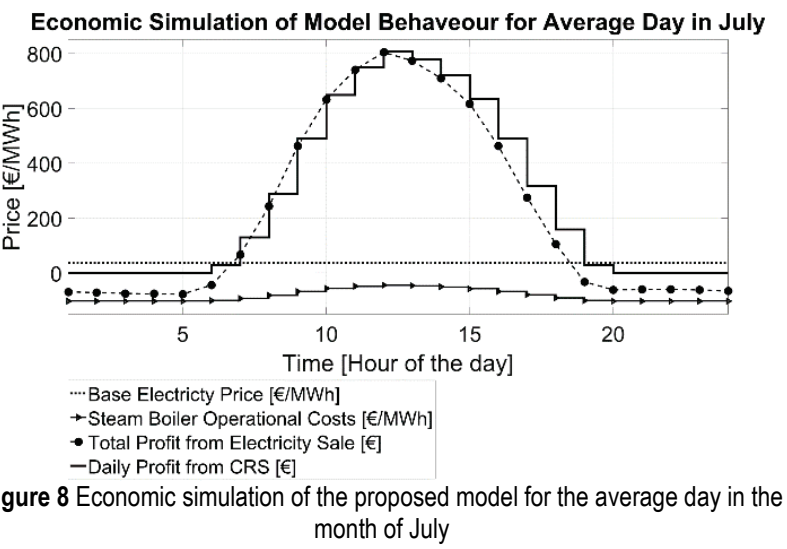

Aforementioned phenomenon is graphically shown in Fig. 7 and Fig. 8. Overall outcome combining Rankine cycle and solar central receiver system based on generated Matlab code is promising. For further exploitation of this solar technology, we should try to achieve higher temperatures in sunbeams' concentrated point in the solar receiver on the top of the central solar tower so that heliostat field could be smaller and would not occupy so much space around the central solar tower. Also, further development and research of working fluid in the solar cycle is made. This is important in order to achieve optimal system performance.

\section{CONCLUSIONS}

In this paper, we present the economic aspect of our pilot model of combining the conventional Rankine cycle with the new technology - solar central receiver system. Applying solar central receiver system to existing Rankine cycles is one of the solutions on how to make thermal power plants less hazardous for our environment and species in it, and at the same time, economical viable when selling the produced electricity on the energy market. Sun and its irradiance offer us a free source of energy, and our model exploits that. In Fig. 9 we can observe the economic performance of the proposed model. We see that with the help of solar power, the proposed model is profitable, considering the optimistic scenario where all the costs for fossil fuel, flue gas cleaning process, upkeeping of infrastructure and other regular maintenance expenses are covered and the proposed model would still make predicted $1075400,00 €$ of profit at the annual level. In Fig. 9 the optimistic scenario is presented with the line-connected dots with the corresponding left y-axis. The sum of monthly individual net profits from the sale of the electricity is the annual economic result of the considered scenario. Taking in the consideration the pessimistic scenario, we need to add to all the aforementioned costs also the cost of the $\mathrm{CO}_{2}$ emission allowances as the form of taxation for the operating thermal power plants. In a case of the pessimistic scenario, taking into consideration that the price of the $\mathrm{CO}_{2}$ emission allowances will be predictably higher with every additional operating year of the thermal power plant, the model would make 353050,00 $€$ loss annually. However, this is also not a bad achievement because without solar addition to the Rankine cycle, the loss of thermal power plant would be significantly higher on annual basis and consequently, also the electricity produced from the thermal unit would be more expensive, when compared with production costs from other electricity production units, in euros per megawatt hour. In Fig. 9, the pessimistic scenario is presented with the bars and corresponding right y-axis. The sum of monthly individual net profits from the sale of the electricity is the annual economic result of the considered pessimistic scenario.

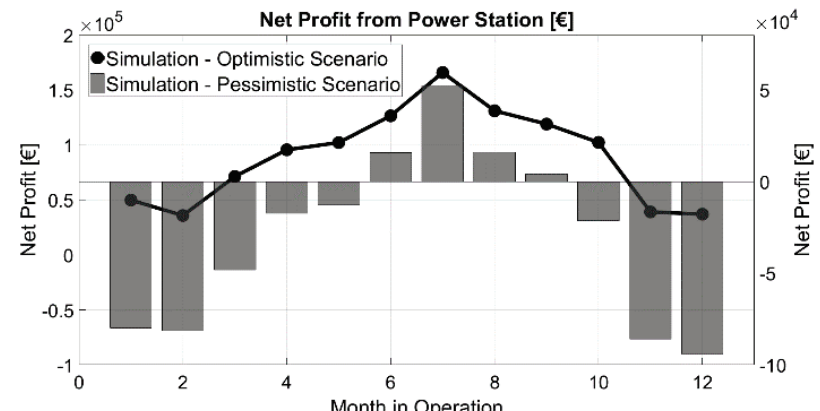

Figure 9 Graph of net profit of thermal power plant electricity sale according to the optimistic scenario (line-connected dots, left y-axis) and a graph of net profit of thermal power plant electricity sale pessimistic scenario (bars, right y-axis)

The proposed model and its economic benefits will have a significant role in the transition from conventional fossil fuels to the renewable sources of the energy, because it enables to cover the base electricity production from the thermal power plant, to maintain the stable electricity distribution network, and it also exploits the renewable energy with its solar central receiver unit and with it, decreases the usage and dependence on the fossil fuels. Further work is focused on how to increase the impact of the solar part on the Rankine cycle so as to make the proposed model more profitable and economically effective, despite the today's demanding energy market. Additionally, our work is focused on how to store produced energy when there is no demand for the electricity, and sell electricity to the network at the higher rates, when there is a high demand for it on the market. That would additionally enhance the economic performance of the proposed model and would definitely make it more interesting to the potential investors.

\section{REFERENCES}

[1] Sanz-Bermejo, J., Gallarado-Natividad, V., GonzalesAguilar, J., \& Romero, M. (2014). Comparative system performance analysis of direct steam generation central receiver solar thermal power plants in megawatt range. Journal of Solar Energy Engineering, 136, (9 pages) 
https://doi.org/10.1115/1.4026279

[2] Romero, M. \& Marcos, M. J. (2000). Design and implementation plan of a $10 \mathrm{MW}$ solar tower power plant based on volumetric - air technology in Seville (Spain). Proceedings of Solar Powers Life - Share the Energy.

[3] Orosz, M. S., Mueller, A., Quolin, S., \& Hemond, H. Small scale solar ORC system for distributed power. Massachusetts Institute of Technology, Civil and Environmental Engineering. Retrieved from: https://orbi.uliege.be/bitstream/2268/24847/1/12156Orosz.pdf

[4] European Union - European Commission (2013). The EU Emission Trading System (EU ETS). European Union, Publications Office.

[5] Rant, Z. (2000). Termodinamika - knjiga za uk in prakso. Fakulteta za strojništvo, Ljubljana. (in Slovene)

[6] Tuma, M. (2004). Energetski sistemi: preskrba z električno energijo in toploto, 3 izdaja. Fakulteta za strojništvo, Ljubljana. (in Slovene)

[7] Horst, H. (1997). Nauk o toploti, 1 natis. Tehniška založba Slovenije, Ljubljana. (in Slovene)

[8] Sergent \& Lundy (2003). Wet Flue Gas Desulphurization Evaluation. Chicago, Illinois, USA.

[9] Babcock \& Wilcox Company (1992). Steam its generation and use, edition 41. Ohio; USA.

[10] Ali, B. H., Gilani, S. I., \& Al-Kayiem, H. H. (2016) Mathematical Modelling of a developed Central Receiver Based on Evacuated Solar Tubes. Mechanical Engineering Department, Universiti Teknologi PETRONAS, Malaysia, published by EDP Sciences.

[11] Bahar, O., Khellaf, A., \& Mohammedi, K. (2013). A review of studies on central receiver solar thermal power plants. Renewable and Sustainable Energy Reviews, 23, 12-39. https://doi.org/10.1016/j.rser.2013.02.017

[12] Zhang, H. L., Baeyens, J., Degreve, J., \& Caceres, G. (2013). Concentrated solar power plants: Review and design methodology. Renewable and Sustainable Energy Reviews, 22, 466-481. https://doi.org/10.1016/j.rser.2013.01.032

[13] Medved, S. (1993). Solarni inženiring - učbenik za vajepripredmetuobnovljivi viri energije in varstvookolja. Fakulteta za strojništvo, Ljubljana. (in Slovene)

[14] Carrizosa, E., Dominiguez-Bravo, C., Fernandez-Cera, E., \& Quero, M. (2015). A heuristic method for simultaneous tower and pattern-free optimization on solar power systems. Computers \& Operations Research, 59, 109-122. https://doi.org/10.1016/j.cor.2014.11.017

[15] Baliff, C., Favrat, D., Aga, V., Romero, M., \& Steinfeld, A. (2013). Germain Augsburger - Thermo-economic optimisation of large solar tower power plants. Ecole Politehique Federale De Lausanne, Suisse.

[16] Nolan, P. S. (1996). Babcock \& Willson Company Emission Control Technologies for Coal-fired Power Plants. Bejing China, Ministry of Electric Power Seminar.

\section{Contact information:}

\section{Martin BRICL, Master of Mechanical Engineering}

(Corresponding author)

University of Maribor, Faculty of Energy Technology,

Laboratory for Thermo-mechanics, Applied Thermal Energy Technologies and Nanotechnologies,

Hočevarjev trg 1, 8270 Krško, Slovenia

martin.bricl@student.um.si

\section{Jurij AVSEC, Vice Dean and Professor PhD}

University of Maribor, Faculty of Energy Technology,

Laboratory for Thermo-mechanics, Applied Thermal Energy Technologies and Nanotechnologies,

Hočevarjev trg 1, 8270 Krško, Slovenia

jurij.avsec@um.si 